\title{
Comparison between the Effect of Clindamycin after Open Reduction Internal Fixation in Jaws and in Limbs
}

\author{
Gharaibeh $\mathrm{M}^{1}$, Al wadiya $\mathrm{A}^{2}$ and Gharaibeh $\mathrm{A}^{3 *}$ \\ ${ }^{1}$ Consultant of oral \& maxillofacial Surgery, Princes Basma Teaching Hospital, Jordan \\ ${ }^{2}$ Royal Derby Hospital, UK, Orthopaedic Surgeon, UK \\ ${ }^{3}$ Department of Orthopaedics and musculoskeletal trauma, Louis Pasteur university \\ Hospital, Slovakia
}

\section{Research Article \\ Volume 2 Issue 2}

Received Date: June 06, 2018

Published Date: June 20, 2018

*Corresponding author: Ahmad Gharaibeh, PhD, MPH, Orthopaedic Surgeon, Department of Orthopaedics and musculoskeletal trauma, Louis Pasteur university Hospital, LF UPJS Kosice, Slovakia, Tel: +421915344317; Email gharaibeh@seznam.cz

\begin{abstract}
Clindamycin is one of the most important antibiotics used against bone infections, in this study we tried to reveal if there is difference between clindamycin effect after open reduction internal fixation (ORIF) in upper and lower jaw operations and the clindamycin effect in open reduction internal fixation (ORIF) of the upper and lower limb bones operations, and to know if the presence of anaerobic bacteria in the oral cavity make any difference of this drug effect comparing with elsewhere bones.

We prepared retrospective study about 260 in-patients during the last 10 years, 130 of them after open reduction internal fixation in limb bones and 130 patients after open reduction and internal fixation ORIF in maxillofacial region, given I.V. Clindamycin. There is no significant difference in the effectiveness of clindamycin in the presence of anaerobic bacteria or not, and clindamycin is the drug of choice in prevention against bone infections after open reduction surgery in the orthopedic and maxillofacial purposes which is agreeing with other studies.
\end{abstract}

Keywords: Bone Infections; Clindamycin; Dental Infections; Prophylaxis Antibiotics

\section{Introduction}

Clindamycin is an antibiotic using for the treatment of several bacterial infections mainly anaerobic infections and particularly those caused by Staphylococcus aureus of aerobic groups [1]. It was firstly used in 1967 [2]. Clindamycin has a primarily bacteriostatic effect [3]. It is a bacterial protein synthesis inhibitor works by inhibiting 


\section{Journal of Orthopedics \& Bone Disorders}

ribosomal translocation, in a similar way to macrolides. Clindamycin is a semisynthetic derivative of Lincomycin [4]. Common side effects include nausea, diarrhea, rash, and pain at the site of injection and it increases the risk of hospital-acquired Clostridium diffusible colitis about fourfold [5]. Clindamycin is not very expensive.

Clindamycin has been used alone for the long-term oral antibiotic of staphylococcal bone and joint infections. It has excellent bone penetration and oral bioavailability. However, a recent literature review shows that it has high bone penetration [6].

Clindamycin is drug of choice in case of sensitivity to penicillin; it is used to prevent endocarditis [7] and to prevent bone infection after open reduction internal fixation for compound bone fractures. Clindamycin is one of the most important antibiotics used against bone infections, in this study we tried to reveal if there is difference between clindamycin effect after ORIF in upper and lower jaw operations and the clindamycin effect on other limb bones operations, and to know if the presence of anaerobic bacteria in the oral cavity make any difference of this drug effect comparing with elsewhere bones.

\section{Material and methods}

\section{Purpose}

The main objective of our work is to evaluate the effectiveness and safety treatment with clindamycin as prophylaxis antibiotics, which is applied intravenously after open reduction and internal fixation in closed fractures in maxillofacial region and open reduction and internal fixation in closed fractures of limbs in a sterile environment.

\section{The Study Sample}

A retrospective study included 260 adult patients with closed fractures divided equally into two groups each of 130 patients in maxillofacial surgery teaching department and orthopaedics teaching department in princes Basma teaching hospital. The patients were randomly assigned into two groups comprised of 130 patients by computer.

\section{Period of Study}

From January $1^{\text {st }} 2008$ to October $31^{\text {st }} 2017$.

A retrospective study in Princes Basma teaching hospital in Irbid, Jordan on 260 in-patients during the last 10 years, 130 of them after open reduction internal fixation in limb bones fractures and 130 patients after open reduction and internal fixation ORIF in maxillofacial region after maxillofacial fractures, treated by i.v. Clindamycin 600mg three times daily (every 8 hours) as prophylaxis of surgical wound infection at least 3 days after and during operation as the guidelines of Princes Basma teaching hospital. We recorded all post-operative infection.

\section{Data Analysis}

Data analysis of the results was processed using the statistical functions of Microsoft Excel.

\section{Results}

The work presented retrospective study to evaluate the post-operative infection in prophylaxis treatment of closed fractures by clindamycin for three days. We retrospectively studied 260 patients with closed traumatic fractures after closed reduction and internal fixation. Computer randomly selected patients. All patients were treated with intra venous clindamycin injections and followed for at least eight months. The first group of 130 patients was treated in maxillofacial teaching department and the second group of 130 patients was treated in orthopaedic teaching department. Post operative order was given, which contains I.V. clindamycin after sensitivity test revealed that only four patients from 130 maxillofacial operations had post operation infections, it means that the failure percentage was $3.07 \%$ (Figure 1, 2).

Orthopedic group had seven patients post-operative infection from 130 patients, which is the failure percentage was $5.38 \%$ (Table 1 ).

In our hospital the usual post op. admission duration is three days, and then the patient is discharged to continue medication orally.

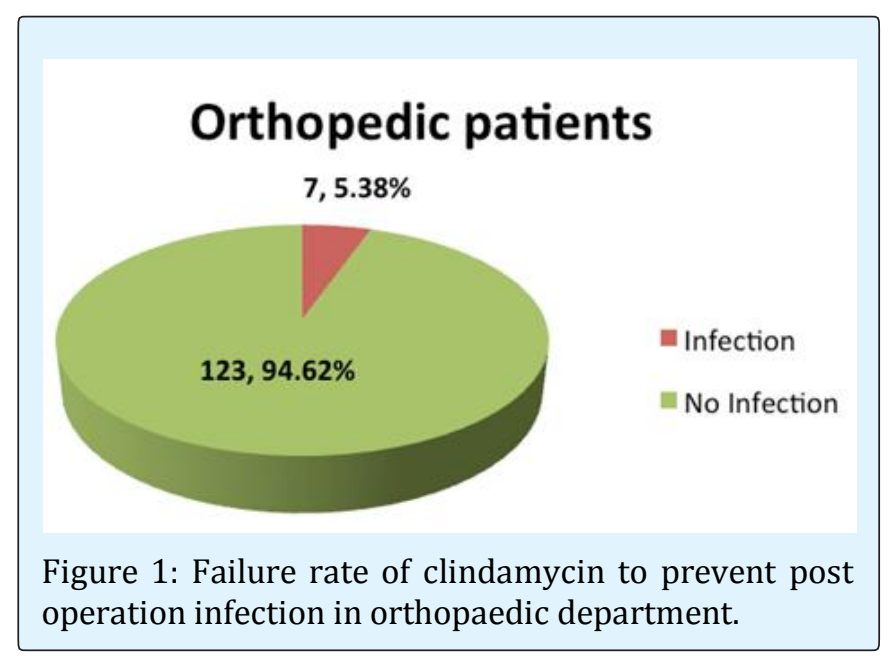




\section{Journal of Orthopedics \& Bone Disorders}

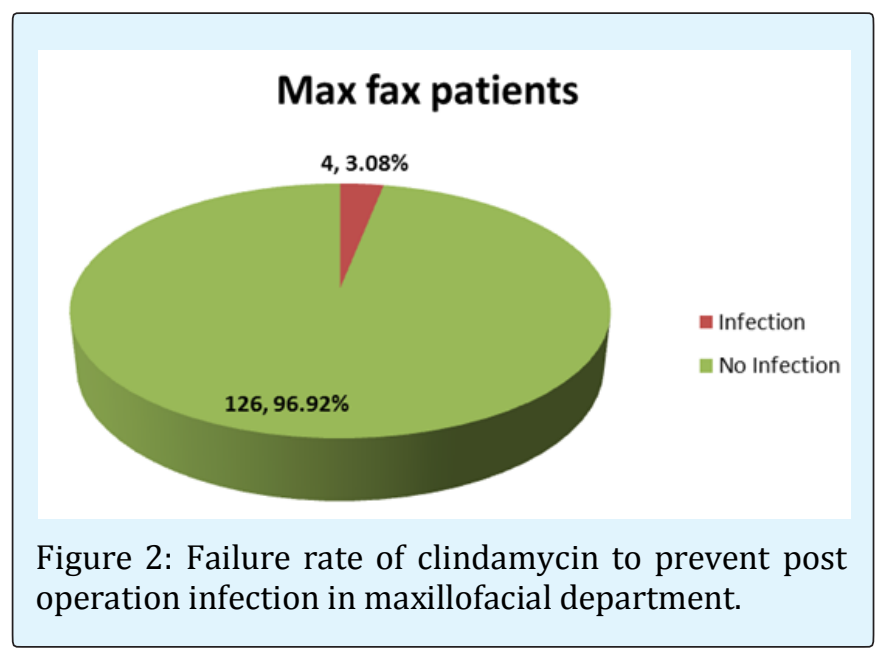

Initial comparison of the absolute values for each group showed that the groups were homogeneous. The four maxillofacial patients were then treated by Cefuroxime sodium combined with metronidazole and the result was good and patients improved. The seven orthopedic patients were treated after failure by cefuroxime sodium only and they got also improved, one patient developed chronic osteomyelitis.

\begin{tabular}{|c|c|c|c|c|}
\hline Department & $\begin{array}{c}\text { No } \\
\text { infection }\end{array}$ & $\begin{array}{c}\text { No } \\
\text { infection }\end{array}$ & $\begin{array}{c}\text { Infectio Infectio } \\
\text { n }\end{array}$ & n \\
\hline $\begin{array}{c}\text { Orthopedic } \\
\text { patients }\end{array}$ & 123 & $94.62 \%$ & 7 & $5.38 \%$ \\
\hline Max fax patients & 126 & $96.92 \%$ & 4 & $3.08 \%$ \\
\hline
\end{tabular}

Table 1: Percentage of infection rate.

\section{Discussion}

Oral cavity is well known that has rich microbial flora especially anaerobic chains [8]. Open reduction of jaw fractures makes the sterility of the operation field a great challenge although we must cover the patient after surgery with suitable antibiotic to avoid post-operative infection.

Surgeons prefer to give metronidazole combined with other antibiotics to fight against aerobic bacteria as first and second generation cephalosporins to get better results but, we used clindamycin as a drug of choice to cover both aerobic and anaerobic bacteria, also clindamycin has good penetration into bone tissue.

Our results explain why the success in the prevention of infections using clindamycin after limbs open reduction slightly more than its use after open reduction in oral cavity because of the presence of high amount of anaerobic bacteria in oral cavity but, in general the failure rate in oral cavity was only $3.07 \%$ which is significantly low. Definitely the use of clindamycin in orthopedic surgery is effective as we find that the failure rate only $1.538 \%$

The side effects of clindamycin is sometimes problematic but, the low rate of these side effects do not exceed $1 \%$ does not disallow to use this antibiotic in wide range [5,9].

\section{Conclusion}

There is no significant difference in the effectiveness of clindamycin in the presence or absence of anaerobic bacteria, and clindamycin is the drug of choice in prevention against bone infections after open reduction surgery in the orthopedic and maxillofacial purposes which is similar to other studies.

Acknowledgment: We thank all the staff of maxillofacial and orthopaedic departments for their kind support.

\section{References}

1. Brook I, Lewis MA, Sándor GK, Jeffcoat M, Samaranayake LP, et al. (2005) Clindamycin in dentistry: more than just effective prophylaxis for endocarditis? Oral Surg Oral Med Oral Pathol Oral Radiol Endod 100(5): 550-558.

2. Sean B Ainsworth (2014) Neonatal Formulary: Drug Use in Pregnancy and the First Year of Life. pp: 162.

3. (2009) Clindamycin. University of Michigan.

4. Birkenmeyer RD, Kagan F (1970) Lincomycin. XI. Synthesis and structure of clindamycin, a potent antibacterial agent. Journal of Medicinal Chemistry 13(4): 616-619.

5. Rossi S (2006) Australian Medicines Handbook. Australian Medicines Handbook, Adelaide.

6. Sendi P, Zemmerli W (2012) Antimicrobial treatment concepts for orthopaedic device-related infection. Clin Microbiol Infect 18(12): 1176-1184.

7. (2018) Clindamycin Hydrochloride. The American Society of Health-System Pharmacists. 


\section{Journal of Orthopedics \& Bone Disorders}

8. Schwiertz Andreas (2016) Microbiota of the human body: implications in health and disease. Springer, Switzerland, pp: 45.
9. De Groot, MCH, Van Puijenbroek ENP (2007) Clindamycin and taste disorders. British Journal of Clinical Pharmacology 64(4): 542-545.

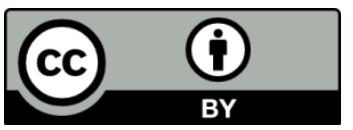

